\title{
Sources of Strain Among Elite UK Track Athletes
}

\author{
Jane McKay \\ University of Strathclyde
}

David Lavallee

Aberystwyth University

\author{
Ailsa G. Niven \\ Heriot-Watt University
}

\author{
Alison White \\ University of Strathclyde
}

\begin{abstract}
Following the theoretical framework of Lazarus and Folkman (1984), recently adapted to sport (Fletcher, Hanton, \& Mellalieu, 2006), 12 elite UK track athletes ( $M$ age $=22.7 ; S D=2.4$ years $)$ participated in semistructured interviews to identify sources of strain. Inductive content analysis identified 11 general dimensions of sources of strain from 664 meaning units, which were subsequently categorized into competitive, organizational, and personal domains. Several sources of strain (e.g., competitive concerns, pressure to perform) were consistent with previous research supporting the suggestion that a core group of stressors may be evident across sports although several sources of strain appeared to be more pertinent to track athletes (e.g., social evaluation and self-presentation concerns) highlighting the need to consider group differences.
\end{abstract}

Research within sport psychology has highlighted the potentially stressful nature of being involved in sport (e.g., Giacobbi, Foore, \& Weinberg, 2004; Noblet \& Gifford, 2002). Stress might influence both the well-being (DiBartolo \& Shaffer, 2002) and performance (Humphrey, Yow, \& Bowden, 2000) of athletes. Therefore, it is important that sport psychologists, and others involved in supporting athletes (e.g., coaches, governing bodies, families) have an understanding of athletes' experiences of stress so that appropriate interventions can be developed to help athletes cope effectively. This descriptive study uses contemporary theory (i.e., Fletcher, Hanton, \& Mellalieu, 2006; Lazarus \& Folkman, 1984) as a guide to gain an insight into elite track athletes' experiences of stress so that sport psychologists can make evidence-based recommendations for supporting these individuals.

Athletes experiences of stress has been a popular area of research, and a number of quantitative and qualitative studies have been undertaken. For example, Gould, Horn, and Spreeman (1983) surveyed athletes on what they perceived caused

McKay is with the Dept. of Sport, Culture, and the Arts, University of Strathclyde, Glasgow, Scotland, UK. Niven is with the School of Life Sciences, Heriot Watt University, Edinburgh, Scotland, UK. Lavallee is with the Dept. of Sport and Exercise, Aberstwyth University, Wales, UK. White (now deceased) was with the Dept. of Sport, Culture, and the Arts, Univ. of Strathclyde, Glasgow, Scotland, UK. 
stress in their sport and a number of quantitative studies have examined stress and coping in sport (e.g., Anshel \& Anderson, 2002). It was recognized, however, that qualitative methods could provide a deeper and less restricted insight into athletes' experiences of stress, and subsequently a number of studies utilizing interviews, focus groups, or both, have been reported. These studies have predominantly focused on identifying what athletes perceive to be sources of stress in several sports, including professional Australian rules football (Noblet \& Gifford, 2002), U.S. high school and recreational golf (Cohn, 1990; Giacobbi, Foore, \& Weinberg, 2004), U.S. elite figure skating (Gould, Jackson, \& Finch, 1993; Scanlan, Stein, \& Ravizza, 1991), U.S. college swimming (Giacobbi, Lynn, et al., 2004), and elite female soccer players (Holt \& Hogg, 2002). From these studies, a large number of sources of stress have been identified and several appear to be common across sports, suggesting that there could be a core group of stressors experienced by all athletes (Noblet \& Gifford). These common stressors include pressure to perform at a high standard, worries about performing poorly, and difficulties balancing sport and nonsport commitments. Despite these commonalities, there is evidence that certain stressors are unique to different sporting environments. For example, Noblet and Gifford also reported stressors that were unique to the Australian footballers they interviewed, including job insecurity and lack of feedback from coaches. Given that variations in groups and their environmental demands can give rise to groups of individuals interpreting the same event differently (Lazarus, 1999), a full understanding of the perceived origins of stress requires consideration of the unique experiences of subgroups of individuals. Therefore, there is a need to examine the stress experiences of athletes from sports and contexts not yet investigated (Giacobbi, Foore, et al., 2004).

Some qualitative studies have focused only on major sources of perceived stress (e.g., Scanlan et al., 1991), and other studies have considered specific types of sources of stress such as competition-induced stress (James \& Collins, 1997) or organizational stress (e.g., Woodman \& Hardy, 2001; Fletcher \& Hanton, 2003). Arguably, to effectively assist athletes in coping with stress, it is important to understand the broad range of stressful experiences encountered by athletes in their specific sport. Fletcher et al. (2006) suggested that recognizing and clearly differentiating between the main types of stress in sport would be useful, and they proposed three major categories of stress including competitive, organizational, and personal stress. Competitive stress was defined by Fletcher and colleagues as "an ongoing transaction between an individual and environmental demands associated primarily and directly with competitive performance" (Hanton, Fletcher \& Coughlan, 2005, p. 1130). Organizational stress was defined as "an ongoing transaction between an individual and the environmental demands associated primarily and directly with the organizations within which he or she is operating" (Hanton et al., 2005, p. 1130), and personal stress was defined as an ongoing transaction between an individual and the environmental demands associated primarily and directly with personal life events (D. Fletcher, personal communication, March 19, 2007). Hanton et al. argued that this approach would allow consideration of the different origins of stressors, the different cognitive processes associated with responses to these stressors, and the appropriateness of different interventions to manage the different stressors. Using these three categories could offer a useful way to organize the numerous sources of stress identified in studies and provide a framework which would be 
accessible to athletes and of use to applied sport psychologists. To date, limited research has employed this distinction, although Hanton et al. compared competitive and organizational stress in elite athletes from a range of sports. The researchers identified a number of competitive stressors relating to performance issues (e.g., injury, opponents) and reported that organizational stressors (e.g., environmental issues, leadership issues) were nearly four times more common. Further research exploring the usefulness of this framework would be of value.

Although the research to date has provided insight into the stress experiences of athletes, there is room for further research to address shortcomings. Specifically, studies to date have not always adhered to the same theoretical basis. Recently, Fletcher et al. (2006) argued for a more rigorous focus on contemporary transactional approaches to stress in sport psychology, which draw heavily from the work of Lazarus (e.g., Lazarus \& Folkman, 1984; Lazarus, 1999). In an attempt to overcome definitional inconsistencies in the use of stress related constructs in sport psychology they proffered useful definitions consistent with the transactional model. Consequently, Fletcher et al. defined stress as "an ongoing process that involves individuals transacting with their environments, making appraisals of the situations they find themselves in, and endeavoring to cope with any issues that may arise" (p. 329; adapted from Lazarus, 1999). This definition is reflected in the above discussion of organizational, competitive, and personal stress. Further, Fletcher et al. defined the environmental demands of the situation as stressors, and the negative psychological, physical and behavioral responses to stressors as strain.

Fletcher et al. (2006) were critical of how the term sources of stress has been used in the sport psychology literature. Although this term was appropriate for early studies that viewed stress as a response to the demands of a situation rather than a process (e.g., Scanlan et al., 1991), this term has continued to be used (e.g., Giacobbi, Foore, et al., 2004). As Fletcher et al. noted, however, the term sources of stress is problematic and should be avoided because it is inconsistent with the transactional definition of stress as a process, which incorporates stressors, strains, appraisals and coping. Instead, they suggested that the term sources of strain might be more appropriate. Many sources of stress studies (e.g., Gould et al., 1993; James \& Collins, 1997) have defined stress for participants using the following definition formulated by Scanlan et al. (1991), which is consistent with Fletcher et al.'s definition of strain:

When we discuss stress or pressure now, I am referring to the negative emotions, feelings, and thoughts that you might have had with respect to your sporting experience. These would include feelings of apprehension, anxiety, muscle tension, nervousness, physical reactions (such as butterflies in the stomach, shaking, or nervous sweating), thoughts centered on worry and self-doubt, and negative statements to yourself (Scanlan et al., 1991, p.105). This definition is more accurately labeled as strain; however, using this definition means that researchers neglect to fully consider the appraisal process that leads to the experience of strain.

Lazarus and Folkman (1984) suggested that the stress process involves primary and secondary appraisal. Primary appraisal involves an assessment as to whether individuals perceive that the situation they are in has important implications for their commitments (Lazarus \& Folkman), goals and well-being (Lazarus, 1999). If 
the individuals perceive the situation as being harmful, threatening, or challenging, then they will appraise the situation as stressful. Secondary appraisal involves an assessment by individuals as to whether they can cope with the demands of the important situation. If individuals perceive that they cannot cope with the situation, then they will likely experience negative psychological, physical, and behavior responses to stressors, which Fletcher et al. (2006) define as strain. The definition used in previous studies means that researchers focused more on the responses emanating from the stress process (e.g., cognitive and somatic anxiety) than the cognitive appraisal process. Consideration of the appraisal process in determining the sources of strain would be more faithful to the transactional nature of Lazarus and Folkman's stress and coping model, and support Fletcher et al.'s (2006) appeals for rigorous adherence to contemporary transactional approaches to stress in sport psychology.

The aim of the current study was to examine sources of strain experienced by elite UK track athletes, a sample which has not previously been considered. The study aims to extend the literature in two important ways. First, by drawing on Fletcher et al.'s (2006) conceptualization of strain and employing a definition that takes account of the cognitive appraisal process, the study will address conceptual limitations of previous studies and adhere more closely to the transactional theory of stress. Second, the study will investigate the broad range of stress experiences of UK track athletes to gain a detailed insight into the stress experience and consider whether the three major categories of stress identified by Fletcher et al. are useful in making sense of these experiences.

\section{Method}

\section{Participants}

Twelve ( 5 men and 7 women) senior elite UK track athletes $(M$ age $=22.67, S D$ $=2.36$ years $)$ participated in the study. All athletes had represented their country during their careers and were members of their national Institute of Sport. The participants had been competing on average for 10 years $(M=10.17, S D=2.07$ years) and ranged in expertise from Great British Junior level to World Championship and Olympic Games standard.

\section{Thick Description of the Context}

In the UK there are 1,400 athletic clubs, and track and field is recognized as one of the country's most successful Olympic sports (UK Athletics, 2000). Track athletes are involved in two competitive seasons, an indoor season extending approximately from December to March and an outdoor season from May to September. The outdoor season is generally the main competition period, with many athletes choosing not to compete indoors and instead undertaking an intensive period of winter training. High performance athletes train all year round and typically train twice a day with one rest day each week. Most athletes train with a training group, and have one main coach who is present at training sessions. Many athletes travel, or even move to another city, to train with a suitable group. Athletes compete in 
domestic competitions, but many also frequently travel abroad to compete at a higher level of competition. Funding for individual athletes is primarily from the revenue of the National Lottery, and at the time of data collection $£ 29$ million (US $\$ 57.5$ million) was allocated to sport annually. Athletes who attain performance standards laid down by UK Athletics are invited to join their home country Sport Institute, and in doing so receive funding and support services, access to superior training facilities, and lifestyle advice. When athletes demonstrate their potential to gain success at a world-class level, they progress onto a World Class Performance Program where they receive enhanced support and higher levels of funding. Performance is reviewed annually and those whose performances are declining or leveling out may be excluded.

\section{Data Collection}

In qualitative inquiry, the researcher is viewed as an instrument of the research (Lincoln \& Guba, 1985), and it is therefore appropriate to provide details of the researchers' background and perspective so that the reader can interpret the researchers' understanding of the data (Elliott, Fischer, \& Rennie, 1999). The first author had extensive experience of competing as an elite track athlete and was familiar with the world of the participants. All researchers had a priori knowledge of sport psychology research on stress. Three of the researchers had experience of supporting athletes in an applied sport psychology context and undertaking qualitative research.

A semistructured interview conducted by the first author was used to gain insight into the participants' perceptions of sources of strain. The interview guide ${ }^{1}$ was developed over several phases following the recommendations of Smith (1997) and Breakwell (1995) and incorporated five major sections including open, nonleading questions, and elaboration prompts and probes that were framed in the language of participants. The first section provided an overview of the purpose and format of the interview and examined background information such as length of involvement in sport, reasons for participation, and goals. The subsequent three sections were designed to explore sources of strain in competition, sources of strain in training, and sources of strain associated with the demands and specific features of the sport. To provide context and adhere to the transactional framework of Lazarus and Folkman (1984), specifically primary and secondary appraisal, participants were asked to discuss encounters where you have felt taxed in meeting the demands and pressures of a situation that has had important consequences for you. Where appropriate, the interviewer drew upon her own experience of strain as an athlete to demonstrate empathy with the interviewees' world (Rubin \& Rubin, 1995). The interview guide was piloted following the phases recommended by Breakwell by testing the comprehensibility of questions on a small group of track athletes and establishing whether responses tapped the issues of importance to the research. In addition, a pilot interview was video recorded and analyzed by six peers, three of whom were experienced qualitative researchers. Following this piloting process, minor modifications were made to the interview schedule and technique (e.g., the interviewer was advised to make greater use of clarification probes and to take more pauses between questions). 


\section{Procedure}

Institutional ethical approval for the study was granted and all participants completed informed consent forms. Participants were invited to participate in the study at the end of the outdoor track season so as to avoid potentially interfering with their psychological preparations for competition. One week before the interview, participants were sent a copy of the interview guide to enable them to familiarize themselves with the interview questions and to facilitate recall of relevant experiences during the interview. At the beginning of each interview, participants were advised that the information they provided would remain confidential, that they could refuse to answer any questions, and that they could terminate the interview at any time. Interviews lasted between $50 \mathrm{~min}$ and $105 \mathrm{~min}$. All interviews were audio-taped and subsequently transcribed, yielding 276 pages of single-spaced text.

\section{Data Analysis}

In the first instance, the researchers ${ }^{2}$ read and reread interview transcripts to become fully familiar with each of the participant's accounts. Each investigator then independently constructed an idiographic profile of each participant, which included a two to three page summary of the participant's background and experiences. These profiles were then collated and a final version of each was developed. While these profiles were not used as data in the subsequent analysis, they served two important purposes. First, as a credibility check they were forwarded to participants to ensure that they accurately represented their experiences and feelings, as communicated during the interview (Elliot, et al., 1999; Lincoln \& Guba, 1985). Second, the idiographic profiles helped provide an overall schema for each participant (Udry, Gould, Bridges, \& Beck, 1997) in which the researchers could contextualize individual quotations during the analysis.

The interviews were then inductively content analyzed by three researchers using the procedures outlined by Scanlan, Stein, and Ravizza (1989), which have since been employed by other qualitative researchers in the field (e.g., Gould et al., 1993; James \& Collins, 1999; Udry et al., 1997). From the interview transcripts, each investigator independently identified meaning units that included quotes that represented a single, recognizable aspect of the participants' experiences (Scanlan, et al., 1991). Each meaning unit $(n=664)$ was 'tagged' with an appropriate label and these represented raw data themes. Raw data themes were copied and pasted onto cards, with corresponding meaning units fixed on the opposite side. Raw data themes with similar meanings were clustered together to form first order themes and a hierarchical structure was developed by identifying relationships between first order themes to establish second order themes. Subsequently, second order themes were clustered together to form third order themes and the inductive process was ongoing until it was no longer possible to further generalize the themes. In some instances second order themes could not be further combined with other themes. The highest order themes in each category were labeled General Dimensions. In some categories the general dimension represented a third order and in other categories a fourth order theme. Following this inductive procedure, the categories were then classified into the preexisting themes of competitive, organizational and personal sources of strain. 
A number of procedures were incorporated into the analysis to increase its credibility following established guidelines (Elliott, et al., 1999; Lincoln \& Guba, 1985). As discussed above, details of the researchers' background were provided and participants were invited to comment on the accuracy of idiographic profiles. In addition, thick description of the context was provided so that readers can determine the transferability of the findings to other contexts and consensus validation between the researchers was sought at all stages of the analysis (i.e., on the labeling of raw data themes and categorization of themes). Where analysts disagreed on the labeling or categorization of themes, discussion was continued until agreement was reached. As a final credibility check, a large poster was drawn up to display the resultant thematic framework in a clear format. All researchers independently examined the framework to ensure that they were satisfied with the categorization of themes. Finally, numerous example quotes from the interviews are included in the results section to allow readers to appraise the fit between the data and the interpretation of the data and so that the 'voices' of the interviewees are heard and can resonate with the reader (Elliott et al.). To aid this process, pseudonym names for each interviewee are used.

\section{Results}

Results derived from the data analysis procedures reflect the collective responses of all 12 participants. A total of 664 raw data themes were identified and condensed into 11 general dimensions and subsequently categorized under the three general themes of competitive, organizational, and personal sources of strain. Each general theme is illustrated fully diagrammatically in Figures 1-3. It is beyond the scope of this paper to describe all raw data themes and elaborate on all first order themes. Therefore, elements of each general dimension will be described and examples of first-order themes with meaning unit quotes will be presented to illustrate the meaning.

\section{Competitive Sources of Strain}

This general theme included issues directly related to performance in competitive environments and included five higher order themes. Competition Concerns (Figure 1a) refer to aspects of and thoughts about competition that participants perceived to be sources of strain. The theme included concerns the athletes had about having self-doubts and lacking confidence in a competitive setting. For example, Katie expressed:

You kind of think, "Oh, God is that it? Am I never going to run fast again, you know, is that the last time I'm going to run a PB?" So you begin to start doubting yourself and doubting your training and just doubting everything that you're doing.

The athletes reported a number of thoughts about competitions that were labeled cognitive concerns. Within this theme, athletes reported having specific concerns about their competitors and being too close to them or feeling inferior to them. For example, Erin commented: 
First Order

Second Order

Third Order

General

- Self-doubts

- Self-doubts about

physical ability

- Uncertainty about form

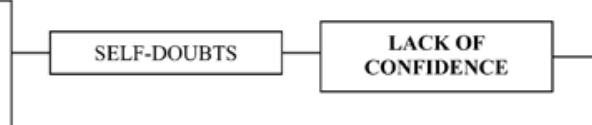

- Feeling inferior to competitors

- Proximity of competitors

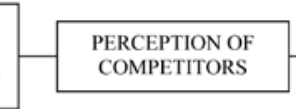

- Concerns about importance of event

- Concerns about the race

- Being preoccupied with thoughts about

competition

- Wanting to back-out of competition

- Having time to think about competition

- Concerns with loss of nervousness

- Excessive nervousness

\section{CONCERNS ABOUT COMPETITION}

- Physical preparation concerns

- Mental preparation problems

Concerns about nutrition

- Technical preparation concerns

- Concerns about sleep

- Lack of competitive experience

- Personal organization concerns

- Fear of being beaten

- Fear of not performing well

- Fear of failure

- Fear of success

- Fear of pain

FEELINGS OF FEAR

- Somatic concerns

- Being unable to relax

SOMATIC CONCERNS

- Being unable to compete/ perform due to injury

- Worries about injury/ reinjury

\section{INJURY CONCERNS}

Figure 1a-Competitive sources of strain: competition concerns.

Very often coming out into the Final and seeing people around you who you know are better than you and you suddenly feel the pressure thinking, "I can't do this, there's so many people here and what am I going to do?"

The athletes also reported that they had worries and concerns about the competition itself, which they perceived as stressful. For example, the athletes reported being 
concerned about being unable to think rationally in a race situation and suddenly realizing that the race is imminent. Some athletes reported that being preoccupied about a competition and finding it difficult to control competitive thoughts during the lead up to competition was stressful. Several athletes also reported having concerns about their preparation for a competition, including concerns with physical, mental, nutritional, and technical preparation, and getting adequate sleep. In addition, concerns with lack of competitive experience and having to be organized so that nothing was forgotten were also stated as sources of strain related to preparation. For example, Arron stated, "You normally travel down the day before and it's always nerve racking making sure you've got all your stuff and not forgetting silly things and you're always sure you've forgotten at least one thing."

Feelings of fear about the competition emerged from comments related to fear of being beaten, not performing well and failing. For example, a number of athletes spoke of their fears of not performing well and being knocked out in preliminary rounds. Becky noted:

It's always scary when you're in a semi-final and you realize that you're in the better semi-final because all the names are in your race and then I suppose you start thinking, "Well what if I don't qualify? What if I don't get into the top four?" and all these kinds of thoughts.

Athletes also commented about the fear of success because the consequences of success such as new opportunities and social obligations could be stressful. Some athletes reported that the anticipation of pain before racing was a source of strain.

Athletes also reported concerns about the way they felt physically before racing, which was labeled somatic concerns and included feeling tired, having heavy legs and being unable to physically relax. For example, Ewan, reported finding the call-up zone particularly stressful and stated:

It's when they say, "You've got 20 minutes in here", and you've got to be able to get up and move, you can't just sit and relax, you've got to be able to get up and keep yourself warm basically and with everybody else about it's not that easy to do.

A number of comments were made by the athletes relating to the stress of injury in competition. Being unable to compete as a result of injury or illness, nor meeting qualifying standards or performing at the desired level was viewed as stressful. Further, worrying about the injury or being reinjured were also identified as sources of strain.

Figure 1b illustrates the four other dimensions that were classified under Competitive Sources of Strain. One theme was labeled Social Evaluation and Self-Presentations Concerns because concerns about being evaluated by others emerged as a source of strain, and specifically, negative comments by others about the athlete's performance and other peoples' doubts about the athlete's effort, ability and coach's expertise were reported as being stressful. Leah reported, "Afterwards it's stressful if people are a bit, not negative, but you know, not content with the way you ran or they question why you're doing it." Further, the athletes also reported self-presentational concerns and were worried about potential evaluation of the 
First Order

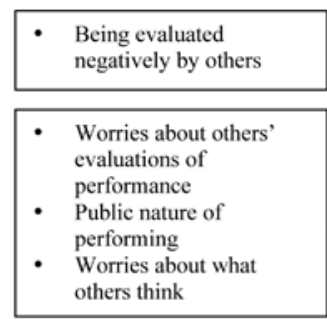

Second Order

General Dimension

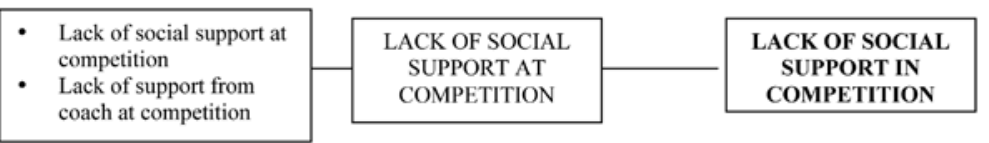

SOCIAL EVALUATION

AND SELF-

PRESENTATIONAL

CONCERNS

\section{SELF-
PRESENTATIONAL}

CONCERNS
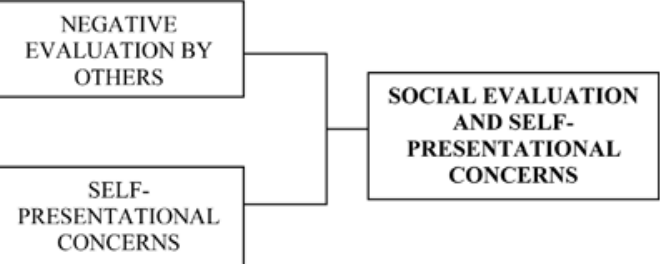
I felt that everybody sort of turned round and looked at me and it was just...I worry a lot about what other people are thinking about me and I don't like it if I think that people don't like me, you know, they were chatting away to each other but they weren't speaking to me and I found that stressful.

The general dimension Lack of Social Support in Competition is also shown in Figure $1 \mathrm{~b}$ and relates to the athletes' concerns about having a lack of support from other individuals involved in the sport at competition. For example, some athletes reported a lack of support from the coach. Katie recalled a competition in which her coach was not present:

I just spoke to him [coach] before I left training and he was just like, you know, "Do your own thing," and all the rest. I hate it when he says that, so yeah that was quite stressful not having him there.

Underperforming in Competition and the consequences of underperforming emerged as significant sources of strain for these athletes (Figure 1b). Specifically in competition the athletes reported the stress of being beaten, pacing the race badly, under-performing, and dealing with the emotional consequences of under-performing. For example, disappointment following an underperformance was identified as a source of strain as noted by Tom: "I could've easily got a medal and there was a huge chance I could've won but because of poor tactics I didn't get into the final and I ran slobbily and I was extremely disappointed in myself."

Having let oneself and others down and facing others after a poor performance were also noted as sources of strain. Athletes reported that facing the media, having to talk and listen to others, the presence of others when the athlete wants to be alone and having to explain reasons for performing poorly when they are unknown were all stressful. These sources of strain are highlighted by Katie's comment:

Just all the questions, that just gets me stressed. I'm like, "Just leave me alone!" Sometimes you just want to be left alone, you know, em, so yeah, when I have to go and speak to people and tell them how I got on I don't like that.

The athletes reported that they felt stressed from pressure to perform well at competition (Figure 1b) and this pressure emanated from themselves to achieve and to perform in time trials and from external sources. External pressure came from coaches' and parents' expectations, pressure from others, and pressure to beat other athletes. Pressure was also evident from sports institutions to gain or maintain funding, and to gain selection for championship races such as the Olympics, as is reflected in this quotation from Rachel:

I think the stress starts a long time before. I mean certainly, when I think about the likes of the Olympics I probably felt that I was worried about it from about a year before because I knew that there was pressure to even, like to get there.

A broader issue of the general dimension Pressure to Perform emerged from a number of comments relating to pressure to perform outstandingly, pressure to perform at championships, pressure to prove effectiveness of training, pressure to run the race according to plan, pressure to leave age group on a "high," and having the opportunity to perform well. This latter source of strain is reflected in 
the following comment from Leah: "When it's a good opportunity, a good race. I think that's stressful, when I've got a chance to get a good time."

\section{Organizational Sources of Strain}

The general theme of Organizational Sources of Strain included five general dimensions primarily and directly associated with the sport organization. Figure $2 \mathrm{a}$ illustrates a number of concerns that emerged relating to training. Experiencing discomfort in training was perceived as stressful and was illustrated by comments related to fear of pain before training, especially during winter training, and actual physical discomfort during training. For example, Arron stated, "In the winter it's more fear 'cause you know it's going to hurt like hell, eh, you're going to be sick, you're going to get lactic." The athletes also reported feeling stressed because they doubted their ability in training and being concerned about changes in the training set-up (e.g., change of coach). The athletes reported that they may be concerned about the content of training and found unexpected changes to training and a lack of specificity in training stressful. Linked to this, the athletes discussed the strain associated with overtraining and how excessive training could lead to weight loss, injury, fatigue and illness. For some athletes the practicalities of training, such as actually getting to training could be stressful if they experienced difficulties with public transport or were late for training. Further, underperforming in training and being concerned about why they were underperforming were identified by the athletes as being sources of strain. Finally, feeling that there was a lack of support in training was also perceived as being stressful.

Figure 2a also illustrates the dimension Negative Aspects of Interpersonal Relationships that reflects athletes' reports that interpersonal relationships could be sources of strain. This dimension included comments about the negative behavior of others, including training partners, competitors, other athletes, the media, track officials, individuals from their life who did not understand the demands of athletics, and the coach. For instance, Sophie mentioned the problems she encountered as a result of her coach's comments about her weight:

He used to turn round and tell me that I was too fat and that I needed to lose weight and everything and I just used to get really $\mathrm{p}^{* * * *} \mathrm{~d}$ off with him, em, it caused probably a lot of problems in my personal life because I used to think about it all the time.

Athletes also mentioned that they experienced conflict with coaches and parents. The most commonly cited stressor within this theme was disagreeing with one's coach regarding the content of training. For example, Katie reported, "Sometimes I think, 'Why is he doing this? I don't feel as if this is going to help me at all. I don't feel as if I'm getting better at my event, it's not helping my endurance', stuff like that." Some athletes also reported the stressful nature of working with two coaches who dislike each other.

Figure $2 b$ includes sources of strain specifically related to the governing body of athletics. Several comments were made regarding the governing body and included concerns about feeling unsupported by members of the governing body during injury, performance decrements, and when inexperienced. For example, Becky remarked, “When I've become injured and haven't performed as well as I 


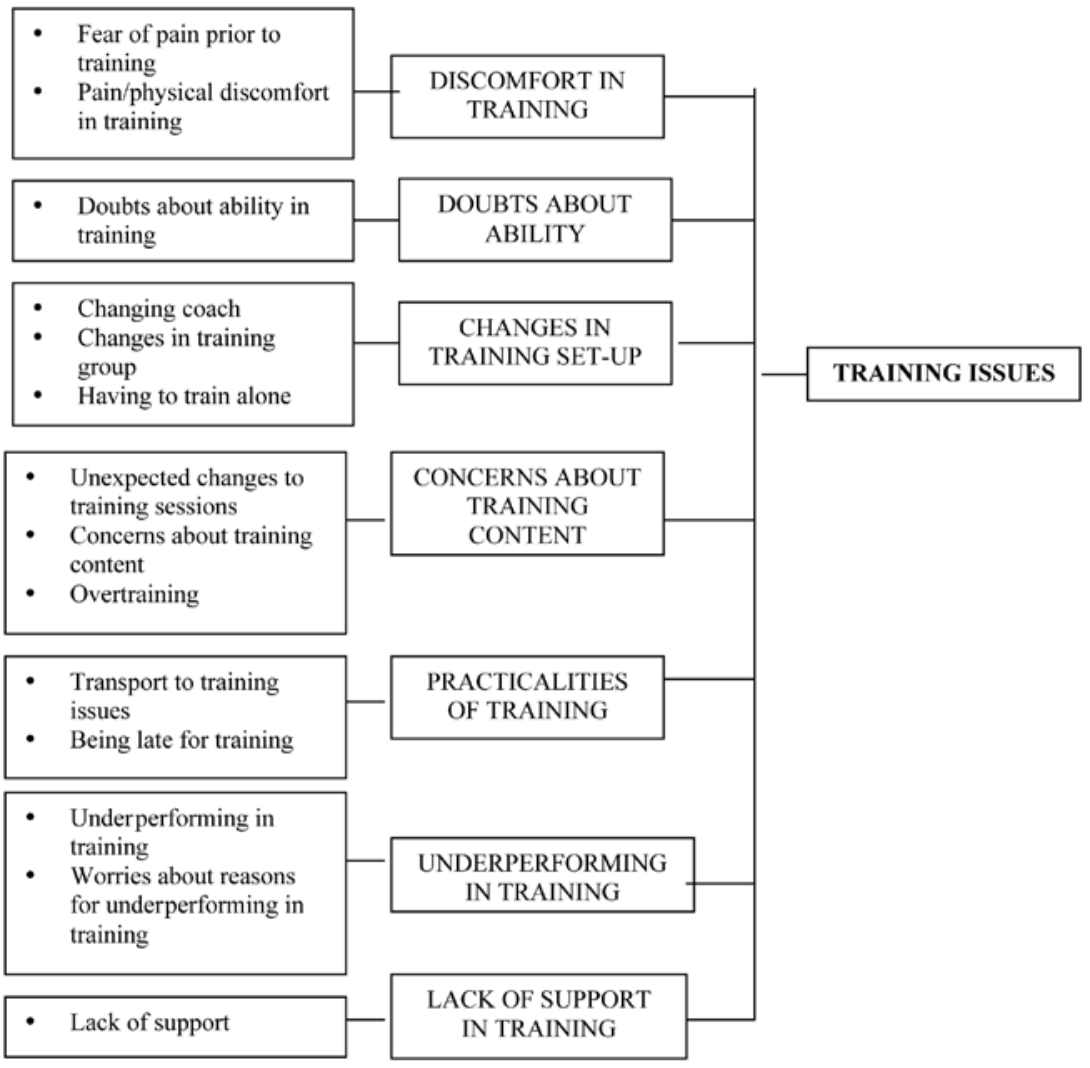

- Negative behavior of training partners

- Negative behavior of competitors

- Negative behavior of other athletes

- Negative behavior of media

- Negative behavior of track officials

- Others' lack of understanding of demands of athletics

- Negative behavior of coach

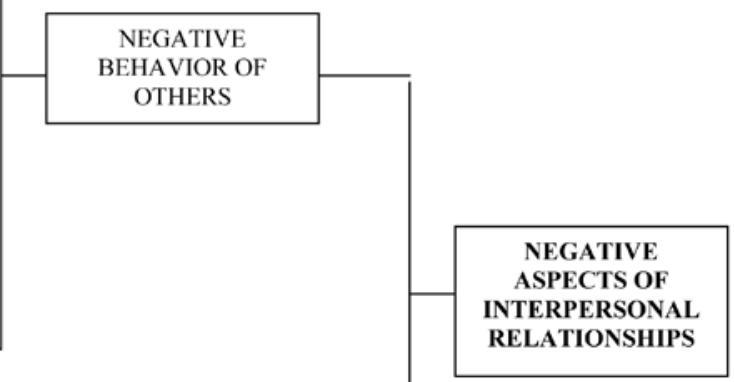

- Conflict with coach

- Conflict with parents

- Conflict between coaches

Figure $\mathbf{2 a}$ - Organizational sources of strain: training issues and negative aspects of interpersonal relationships. 
should, people just completely ignore you. People within the governing body just don't pay attention to you and just don't ask what's happening." Further concerns relating to the governing body included comments relating to perceived inconsistencies in funding allocation procedures and loss of funding. Leah, for example, felt that funding was frequently unfairly distributed, observing that, "it seems to be the same people that get it [funding] and once they've got it they get more and more." In addition, selection procedures that were perceived to be unfair, out with the athlete's control, and unclear were identified as sources of strain. For example, Jamie commented, "Sometimes with national athletics teams I feel as if there's a lot of pettiness and sort of definitely a lot of nepotism. It's like who you know rather than how good you are." Finally, athletes also reported that it was stressful when they felt rules were applied inconsistently (e.g., inconsistencies in wind gauge reading rules). Scheduling issues also emerged as an organizational factor that could be stressful. Athletes identified poor or undesirable timetabling at competitions, having to decide between competitions that clash, and having to compete early in the morning as sources of strain. Dealing with a positive doping test also emerged as a source of strain and included comments about the strain associated with being informed of a positive doping test, having to inform one's parents of the test result, prolonging of the athlete's athletic career because of suspension from competition, having an unsuccessful court hearing, and realizing that one's athletic season was over.

The athletes reported that the environmental conditions (Figure 2b) of competing could be stressful. Specifically, concerns with race and lane conditions included comments relating to having to use starting blocks, not having suitable race conditions and being drawn in unfavorable lanes and between faster competitors. Arron, for example, commented, "You find your lane draw out and they've [competitors] got a better lane draw than you and you're in lane eight and that's stressful." The athletes also reported concerns relating to lack of control over weather and the consequences of adverse weather conditions on performances. For instance, Katie stated:

If it's like my last chance to run a good time then you always really want it to be good weather and you turn up and it's really windy and I'm like, "Oh no, there's no way I can run a fast time when it's this windy" and yeah, so that does contribute a lot to stress.

A general dimension of Personal Issues Related to the Organization (Figure 2c) included issues related to the personal and lifestyle demands of being an athlete. Some athletes reported that the athletic life could be stressful because they were unable to have a 'normal' life because of training and competing away from home and the general demands of the athletic lifestyle. Arron illustrates this source of strain in the following comment: "I suppose being sick and struggling and not running well and yeah, worrying about being skint and not being able to have a sort of normal life-boozing and birds and stuff." Some athletes reported that they experienced difficulties in maintaining relationships, dealing with the time and financial demands of being an athlete and having to make sacrifices due to athletics. For example, Becky reported: 
First Order

Second Order

General Dimension

- Perceived lack of support from governing body representatives

- Funding issues

- Selection issues

- Inconsistencies in application of rules

- Finding appropriate standard competition

- Consequences of poor/undesirable timetabling

- Delays in competition schedule caused by poor organization

- Issues related to positive doping test
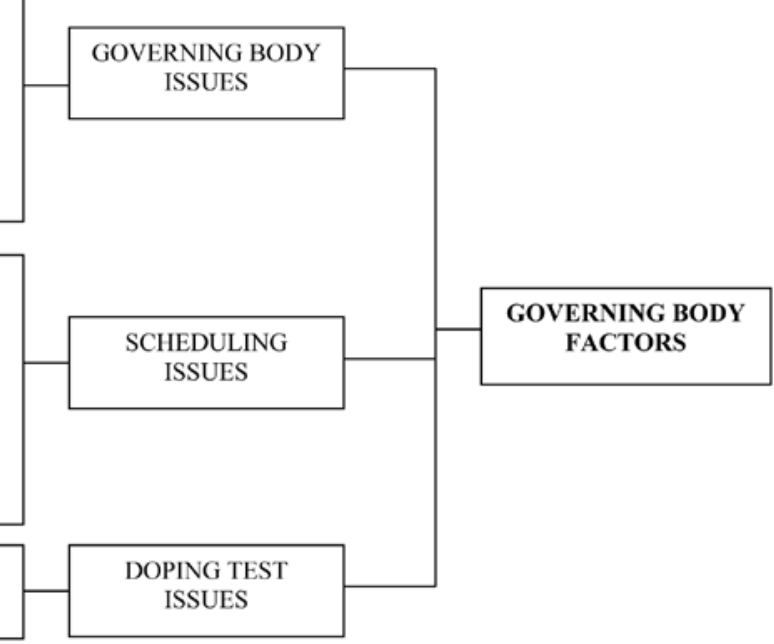

- Lane conditions

- Race condition

\section{LANE AND RACE CONDITIONS}

- Lack of control over weather

- Consequences of adverse weather conditions

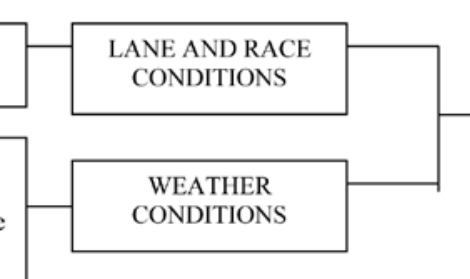

ENVIRONMENTAL

Figure $\mathbf{2 b}$ - Organizational sources of strain: governing body factors and environmental conditions in competition.

I feel as if I'm putting the rest of my life on hold at the moment and even though I've said it isn't an important part of my life, a major part of my life is my [job] and I'm putting that on hold for an entire year.

The dimension of loss of motivation is also included in the Personal Issues dimension and refers to concerns some athletes had that they had lost motivation to train, compete, or continue their participation in the sport. Some athletes reported that on occasion they questioned their commitment to athletics following injury and poor performances. For example, Arron reported, "If you're injured then it's hard to keep on the straight and narrow ... it's like, 'Oh what's the point, I'm not going to be doing much anyway, f*** it, why am I running, what's the point?’” 
First Order

Second Order

General Dimension

- Changes when training/competing away from home

- Consequences of athletic lifestyle

- Difficulties maintaining personal relationships

- Making sacrifices

- Time demands

- Financial demands

- Questioning commitment to athletics

- Loss of motivation to participate in athletics

- Loss of motivation to compete

- Loss of motivation to train
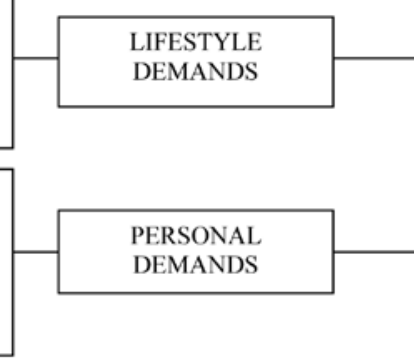

- Difficulties dealing with injury

- Ambiguity surrounding injury severity/treatment

- Unpredictability of injury occurrence

- Injury/illness susceptibility

- Lack of social and medical support when injured

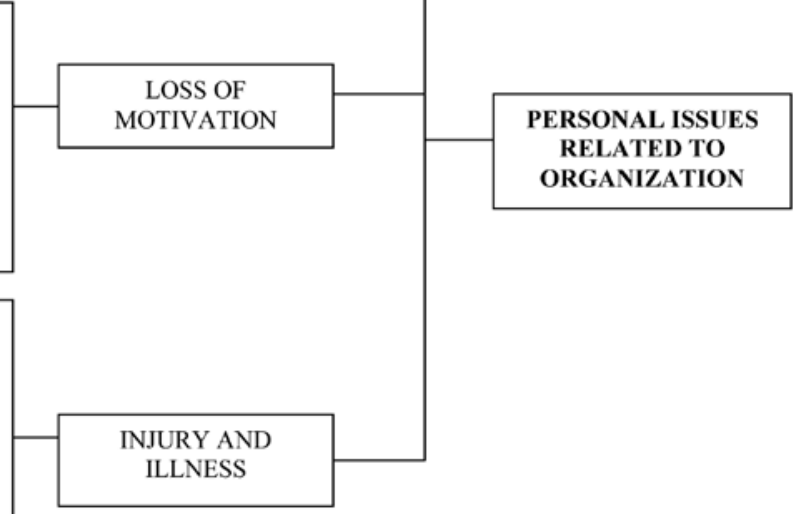

Figure 2c - Organizational sources of strain: personal issues.

Finally, the Personal Issues theme included comments from the athletes relating to the stress of injury and illness. A number of comments emerged relating to difficulties dealing with injury and how the uncertainty about cause and treatment of injury and ambiguity surrounding injury severity could be stressful. For example, Jamie recalled:

Everybody I went to see had different ideas of what the knee problem was, but no one could actually identify it and it took six to seven months to disappear and it had to go away on its own. No treatment helped, no ultrasound, no massage, not anything helped it at all.

Concerns about the unpredictability of injury occurrence emerged and revolved around having injuries occur at inconvenient or unexpected times such as while warming-up, at the start of the season, and when performing well. For example, 
Becky stated: "You can't plan on getting an injury, so whenever you do get one it's always unexpected and it's always a point where you think, 'Well why does it have to happen now?'" The athletes also reported worrying about being susceptible to injury and illness, sustaining repeated injury, and being on the edge of experiencing an injury. Athletes also suggested that the lack of support provided by the governing body, medical support, friends and other people in general was stressful.

\section{Personal Sources of Strain}

The general theme focusing primarily and directly on personal life events included only the general dimension of Life Stress, which related to events outside of athletics (Figure 3). For example, university commitments and lifestyle changes associated with moving house or job were perceived as stressful. Some athletes reported that dealing with traumatic events (e.g., death of a significant other) was difficult. Although the death of a brother is obviously a personal issue, Ewan commented how this influenced his own and fellow athletes experiences at competition: 'They all knew him really well, so it was hard for them as well, so that was a pretty hard race to do, really hard to try and keep my mind off everything else that was going on."

\section{Discussion}

This study aimed to adhere to the transactional theory of stress to identify sources of strain experienced by a group of international track athletes, so that the information can be used to assist sport psychologists working with this population. The qualitative results provided a rich insight into the athletes' experiences and highlighted the extensive range of sources of strain experienced from competitive, organizational and personal contexts (Fletcher et al., 2006). Although commonalities in sources of strain were evident, no single source of strain was reported by all 12 athletes. This finding replicates previous studies that have found vast individual differences in sources of strain (e.g., Gould, et al., 1993; Scanlan, et al., 1991), and emphasizes the importance of individual differences in the stress process (Lazarus \& Folkman, 1984).

Several of the sources of strain identified are consistent with previous research, and add support to the suggestion that there is a core group of stressors experienced across sports (Noblet \& Gifford, 2002). For example, the four most frequently cited general dimensions of stress reported in previous studies were also identified in this investigation. These categories included Competitive Concerns (e.g., Cohn, 1990; Holt \& Hogg, 2002), Pressure to Perform (e.g., Gould, et al., 1993; Noblet \& Gifford), Lifestyle Demands (e.g., Cohn; Gould, et al.) and Negative Aspects of Interpersonal Relationships (e.g., Holt \& Hogg; Scanlan, et al., 1991). In addition, many of the lower-order themes that made up the general dimensions from this study also replicated those reported in earlier research. For example, themes within the competitive sources of strain dimension that had been previously noted, included Self-doubts (Gould, et al.; James \& Collins, 1997), Perceptions of Competitors (Gould, et al.; Hanton, et al., 2005; James \& Collins), Concerns about Competition (James \& Collins; Scanlan, et al.), Pressure to Perform (Hanton et al.), and the emergence of cognitive and somatic concerns paralleled the finding of cognitive and somatic symptoms of anxiety (Gould, et al.; Holt \& Hogg; James \& Collins; 


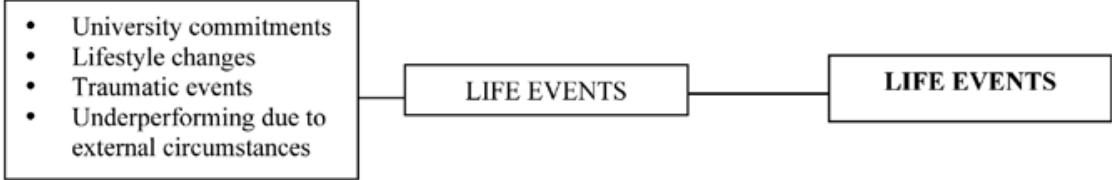

Figure 3 - Personal sources of strain: life events.

Scanlan, et al.). Similarities were also evident in organizational sources of strain relating to athletic lifestyle demands that emerged in this study and previous studies, including difficulties maintaining personal relationships (Cohn; Noblet \& Gifford), time and financial demands (Cohn; Gould, et al.; Scanlan, et al.), and being unable to have a 'normal' life (Scanlan, et al.). Replication of these findings indicates that certain demands are consistent across sports and sport psychologists may deal with common issues in different sports.

Additional sources of strain that were identified in this study have not been so prominent in other studies, and may be particularly pertinent to this sample. For example the dimension Social Evaluation and Self-Presentational Concerns which included concerns about what others think, feeling the need to impress others and fear of public humiliation, emerged as a major theme in this study but not in others. An exception was James and Collins (1997) who focused specifically on self-presentational mechanisms underlying sources of competitive stress. It is possible that the salience of social evaluation and self-presentational concerns in the current study can be explained by the nature of competing in track athletics. In track athletics athletes compete individually in front of a number of people, which results in greater potential for evaluation by many others. Similarly, underperforming emerged as a major dimension in this study and this may be due partly to the individual nature of the sport in which responsibility for under-performance cannot easily be attributed to others. While this study identified sources of strain that may be unique to the individual nature of the sport concerned, by contrast, some strain sources that have been identified in previous work in team sports were not relevant to the athletes in this study (e.g., not feeling part of the group; cliques between players; Noblet \& Gifford, 2002).

Within the general theme of Organizational Sources of Strain a number of issues relating specifically to governing body issues emerged including selection issues, funding issues and lack of support from members of the sport organization. These themes have also not previously emerged as major categories of stress in studies investigating sources of strain across the totality of athletes' sporting experiences. Nevertheless, the findings from this study do support Woodman and Hardy's (2001), and Fletcher and Hanton's (2003) UK-based research specifically on organizational sources of strain in sport. It may be that organizational factors are more relevant for UK athletes in the current environment of Lottery funding and selection criteria than for athletes in other areas. These findings highlight the need for sport organizations to provide clear and transparent team selection and 
funding criteria and to provide appropriate support to performers. In addition, the findings support the suggestion that sport psychologists might have an important role to play in the stress management of the sport organizations in which they are involved (Woodman \& Hardy), and should therefore be appropriately trained (Hanton et al., 2005).

A number of sources of strain identified in this study with elite UK athletes are consistent with previous findings supporting the suggestion that there are common experiences across samples. Nevertheless, it was evident that some sources of strain were particularly relevant to this group advancing our understanding of perceived sources of strain in elite UK track athletes and highlighting the need to consider group differences in fully understanding causes of strain. It was possible to categorize the athletes' experiences into competitive, organizational, and personal sources of strain adding support to Fletcher et al.'s (2006) proposed framework for understanding stress in sport. The athletes reported few personal issues that were unrelated to sport, however, although given that the study was focused on strain and sport this was perhaps unsurprising. It was not the purpose of this study to include a frequency count of the sources of strain, but it was clear that the organizational category contained considerably more dimensions than the competitive and personal categories. This finding is consistent with Hanton et al.'s (2005) study which reported four times more organizational than competitive sources of strain. It should be noted, however, that the definition of organizational stress as "an ongoing transaction between an individual and the environmental demands associated primarily and directly with the organization within which the athlete is operating" (Hanton et al., p. 1130.) is a very broad definition and is likely to lead to a large number of identified categories. Indeed, in this study and others (Hanton et al.; Woodman \& Hardy, 2001) identified sources of organizational strain included a wide range of experiences including training, injury, and team issues. Hanton et al. argued that it is useful to differentiate between major categories of stress to allow consideration of the different origins of stressors, the different cognitive processes associated with responses to these stressors, and the appropriateness of different interventions to manage the different stressors. It is suggested, however, that the category of organizational stress is too broad to be fully useful in an applied setting. For example, the cognitive processes and appropriate interventions to deal with injury and team issues are likely to be different and subdividing the category of organizational stress could be appropriate.

A strength of this study was that it adhered to the transactional model of stress, and employed a definition that accounted for the cognitive appraisal process. The retrospective nature of the study meant that it was not possible to fully consider the dynamic nature of cognitive appraisal and the process nature of stress, however. An alternative methodology using a narrative analysis or idiographic longitudinal approach would allow the unfolding of the stress process to be revealed. The descriptive nature of this study might also be viewed as a limitation. While we maintain that the description provided by this research is of value in itself because it provides insight into athletes' experiences, it does not offer an insight into the mechanisms by which sources of strain are meaningful to athletes. For example, consideration of the influence of individual differences (e.g., athletic identity, perfectionism) may help explain variation in sources of strain encountered and would be an appropriate area for future research. 


\section{Conclusion}

In summary, this study has used contemporary theory to gain a comprehensive insight into the sources of strain experienced by elite UK track athletes. The findings add to the growing body of research on stress in sport, and support Fletcher et al.'s (2006) suggestion that the sources of strain experienced by athletes can be conceptualized within three domains; competitive, organizational and personal. Although, it was suggested that subdividing the organizational domain might aid practical application. The findings further support the suggestion that there may be a core group of stressors experienced by all athletes. Nevertheless, some sources of strain were more pronounced in this study than previous studies highlighting that group differences may exist and that, to fully understand the origins of strain, it is important to consider the unique nature of different sports. These findings provide valuable information for sport psychologists, coaches and governing bodies aiming to effectively support track athletes to enhance their well-being and performances.

\section{Notes}

1. A copy of the interview schedule is available from the second author on request.

2. The first, second and fourth authors were involved in the analysis.

\section{References}

Anshel, M.H., \& Anderson, D.I. (2002). Coping with acute stress in sport: Linking athletes' coping style, coping strategies, affect, and motor performance. Anxiety, Stress and Coping. International Journal (Toronto, Ont.), 15, 193-209.

Breakwell, G. (1995). Interviewing. In G.M. Breakwell, S. Hammond, \& C. Fife-Shaw (Eds.), Research methods in psychology (pp. 194-212). London: Sage.

Cohn, P.J. (1990). An exploratory study on sources of stress and athlete burnout in youth golf. The Sport Psychologist, 4, 95-106.

DiBartolo, P.M., \& Shaffer, C. (2002). A comparison of female college athletes and nonathletes: Eating disorder symptomatology and psychological well-being. Journal of Sport and Exercise Psychology, 24, 33-42.

Elliot, R., Fischer, C.T., \& Rennie, D.L. (1999). Evolving guidelines for publication of qualitative research studies in psychology and related fields. The British Journal of Clinical Psychology, 38, 215-229.

Fletcher, D., \& Hanton, S. (2003). Sources of organizational stress in elite sports performers. The Sport Psychologist, 17, 175-195.

Fletcher, D., Hanton, S., \& Mellalieu, S.D. (2006). An organizational stress review: Conceptual and theoretical issues in competitive sport. In S. Hanton \& S.D. Mellalieu (Eds.), Literature reviews in sport psychology (pp. 321-374). New York: Nova Science.

Giacobbi, P.R., Foore, B., \& Weinberg, R.S. (2004). Broken clubs and expletives: The sources of stress and coping responses of skilled and moderately skilled golfers. Journal of Applied Sport Psychology, 16, 166-182.

Giacobbi, P.R., Lynn, T.K., Wetherington, J.M., Jenkins, J., Bodendorf, M., \& Langley, B. (2004). Stress and coping during the transition to university for first-year female athletes. The Sport Psychologist, 18, 1-20. 
Gould, D., Horn, T., \& Spreeman, J. (1983). Sources of stress in junior elite wrestlers. Journal of Sport Psychology, 5, 159-171.

Gould, D., Jackson, S., \& Finch, L. (1993). Sources of stress in national champion figure skaters. Journal of Sport and Exercise Psychology, 15, 134-159.

Hanton, S., Fletcher, D., \& Coughlan, G. (2005). Stress in elite sport performers: A comparative study of competitive and organizational stressors. Journal of Sports Sciences, $23,1129-1141$.

Holt, N.L., \& Hogg, J.M. (2002). Perceptions of stress and coping during preparations for the 1999 women's soccer world cup finals. The Sport Psychologist, 16, 251-271.

Humphrey, J.H., Yow, D.A., \& Bowden, W.W. (2000). Stress in college athletics: Causes, consequences, coping. Binghamton, NY: The Haworth Half-Court Press.

James, B., \& Collins, D. (1997). Self-presentational sources of competitive stress during performance. Journal of Sport and Exercise Psychology, 19, 17-35.

Lazarus, R.S. (1999). Stress and emotion: A new synthesis. New York: Springer.

Lazarus, R.S., \& Folkman, S. (1984). Stress, appraisal, and coping. New York: Springer.

Lincoln, Y.S., \& Guba, E.G. (1985). Naturalistic inquiry. London: Sage.

Noblet, A.J., \& Gifford, S.M. (2002). The sources of stress experienced by professional Australian footballers. Journal of Applied Sport Psychology, 14, 1-13.

Rubin, H.J., \& Rubin, I.S. (1995). Qualitative interviewing: The art of hearing data. London: Sage.

Scanlan, T.K., Stein, G.L., \& Ravizza, K. (1989). An in-depth study of former elite figure skaters: II. Sources of enjoyment. Journal of Sport and Exercise Psychology, 11, 65-83.

Scanlan, T.K., Stein, G.L., \& Ravizza, K. (1991). An in-depth study of former elite figure skaters: III. Sources of stress. Journal of Sport and Exercise Psychology, 13, 103-120.

Smith, J.A. (1997). Semi-structured interviews and qualitative analysis. In J.A. Smith, R. Harre, \& L. Van Langenhove (Eds.), Rethinking methods in psychology (pp. 9-26). London: Sage.

Udry, E., Gould, D., Bridges, D., \& Beck, L. (1997). Down but not out: Athlete responses to season-ending injuries. Journal of Sport and Exercise Psychology, 19, 229-248.

UK Athletics (2000). Fun to fulfilment: The development of athletics in the U.K. U.K.: Athletics: Birmingham.

Woodman, T., \& Hardy, L. (2001). A case study of organizational stress in elite sport. Journal of Applied Sport Psychology, 13, 207-238.

Manuscript submitted: June 1, 2006 